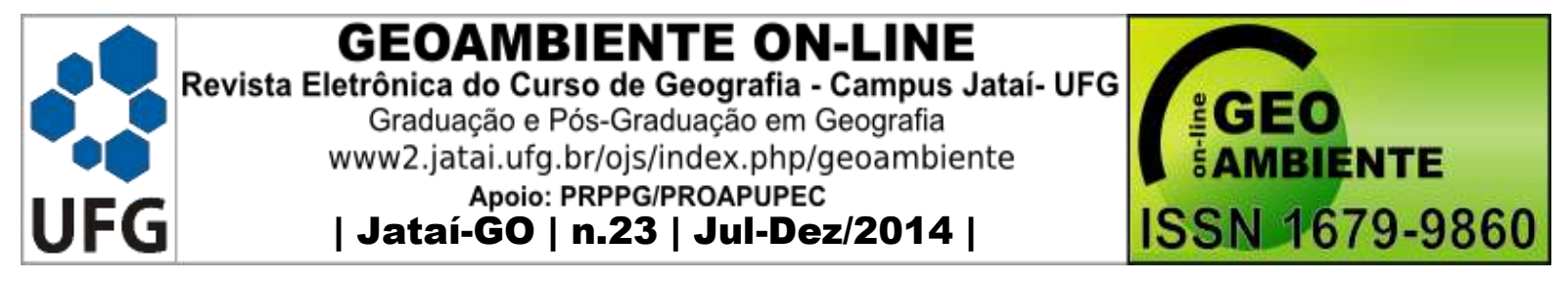

\title{
FLORAÇÃO DE COMUNIDADE PIROFÍTICA NO ENTORNO DO PARQUE NACIONAL DA CHAPADA DOS VEADEIROS - ESTADO DE GOIÁS, BRASIL
}

Carlos de Melo e Silva Neto ${ }^{1}$, Vandervilson Alves Carneiro ${ }^{2}$, Lyne Sussuarana Pereira ${ }^{3}$, Bruno Bastos Gonçalves ${ }^{4}$

(1 - Universidade Federal de Goiás, Doutorando em Agronomia - Produção Vegetal, carloskoa@gmail.com, 2 - Universidade Federal de Goiás, Doutorando em Geografia, Docente da UEG-UnUCET (Anápolis, GO), profvandervilson@hotmail.com, 3 - SENAI Serviço Nacional de Aprendizagem Industrial, Docente, Mestre em Engenharia Agrícola / UEG - Universidade Estadual de Goiás, sussuarana.fly@gmail.com, Universidade Estadual Paulista Júlio Mesquita Filho (Campus FCAV, Jaboticabal - SP), Doutorando em Aquicultura, goncalves.b.b@gmail.com)

\section{RESUMO}

Esse estudo objetiva demonstrar a composição florística de populações que florescem após a passagem do fogo em uma área de Cerrado rupestre. Os estudos foram conduzidos no final da estação seca em uma área queimada de Cerrado rupestre no entorno do Parque Nacional da Chapada dos Veadeiros, Goiás, Brasil. Todos os indivíduos que se encontravam em estado reprodutivo na área foram fotografados e coletados para identificação. Foi realizada observação focal (24hs) para visualizar visitantes florais em Dyckia cf. areniticola Leme, por ser a planta em floração mais abundante na área. No total foram encontradas 16 espécies em estado reprodutivo, de 15 gêneros diferentes e 11 famílias botânicas. As famílias que tiveram maior número de espécies encontradas na área são Amaranthacea (3 spp.); Asteraceae; Bromeliaceae e Cyperaceae ( 2 spp.). Exceto pelas espécies da família Cyperaceae, todas as outras espécies florescem e fornecem recursos para visitantes florais e polinizadores. Dentre as espécies, quatro são endêmicas para o Cerrado (Inulopsis camporum; Gomphrena cf. lanigera; Crumenaria choretroides e Bromelia glaziovii), sendo que G. lanigera e B. glaziovii só ocorrem em Goiás e Minas Gerais. Além disso, D. cf. areniticola é considerado nova ocorrência para o Estado de Goiás. 


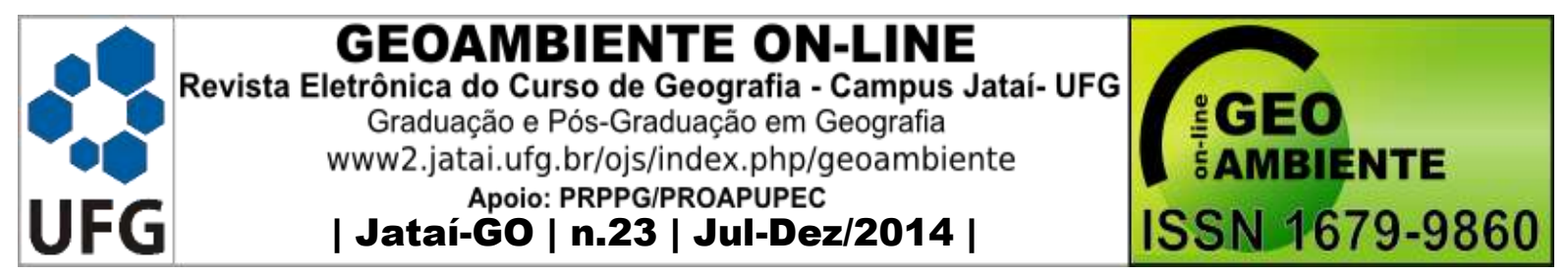

Palavras-chave: Fogo. Florescimento. Amaranthaceae. Asteraceae.

\section{ABSTRACT \\ FLOWERING PIROFITE COMMUNITY AROUND THE NATIONAL PARK OF CHAPADA DOS VEADEIROS - STATE OF GOIÁS, BRAZIL.}

This study aims to demonstrate the floristic composition of populations that bloom after the passage of fire in an area of Cerrado (Brazilian Savanna). The studies were conducted at the end of the dry season in a burned area of Cerrado rupestre surrounding the National Park of Chapada dos Veadeiros, Goiás, Brazil. All plants that were in reproductive status in the area were photographed and collected for identification. Were performed focal observation (24h) to display floral visitors in Dyckia cf. areniticola Leme. That was the most abundant flowering plant in the area. In total, 16 species were found in the reproductive status of 15 different genera and 11 plant families. Families who had a greater number of species found in the area are Amaranthacea (3 spp.), Asteraceae, Bromeliaceae and Cyperaceae (2 spp.). Except for the species in the family Cyperaceae, all other specimens bloom and provide resources for floral visitors and pollinators. Among the species, four are endemic to Cerrado (Inulopsis camporum; Gomphrena cf. lanigera; Crumenaria choretroides and Bromelia glaziovii), and G. lanigera and B. glaziovii only occur in Goiás and Minas Gerais. Furthermore, D. cf. areniticola is a new record to Goiás.

Keywords: Fire. Blooming. Amaranthaceae. Asteraceae.

\section{RESUMEN}

\section{FLORACIÓN DE LA COMUNIDAD PIROFÍTICA EN ALREDEDORES DEL PARQUE NACIONAL DE LA CHAPADA DOS VEADEIROS EM EL ESTADO DE GOIÁS, BRASIL}

Este estudio tiene como objetivo demostrar la composición florística de las poblaciones que florecen después del paso del fuego en Cerrado rupestre. Los estudios se realizaron al final de la estación seca en un área quemada de Cerrado rupestre que rodea el Parque Nacional Chapada dos Veadeiros, Goiás, Brasil. Todas las personas que se encontraban en estado reproductivo en la zona fueron fotografiadas y se recogen para su identificación. Se celebró la observación focal (24 horas) para mostrar los visitantes florales en Dyckia cf. areniticola 


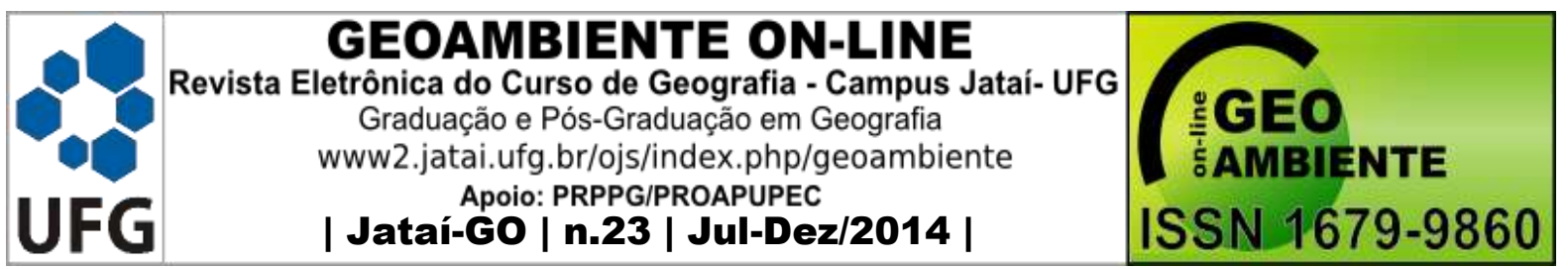

Leme, siendo la planta de floración más abundante en la zona. En total se encontraron 16 especies en estado reproductivo de 15 géneros diferentes y 11 familias botánicas. Las familias que tenían un mayor número de especies que se encuentran en la zona son Amaranthacea (3 spp.); Asteraceae; Bromeliaceae y Cyperaceae (2 spp.). Con excepción de las especies de la familia Cyperaceae, todas las demás especies florecen y proporcionan recursos para los visitantes de flores y polinizadores. Entre las especies, cuatro son endémicas en el Cerrado (Inulopsis camporum; Gomphrena cf. lanigera; Crumenaria choretroides y Bromelia glaziovii), G. lanigera y B. glaziovii sólo se producen en Goiás y Minas Gerais. Además, D. cf. areniticola se considera un nuevo récord para el Estado de Goiás.

Palabras clave: Fuego. Floración. Amaranthaceae. Asteraceae

\section{INTRODUÇÃO}

O Cerrado Rupestre ${ }^{1}$ é um tipo fisionômico constituído por um estrato herbáceo, arbustos e pequenas arvoretas, crescendo sob neossolos litólicos (RIBEIRO; WALTER, 1998). Esta fisionomia apresenta uma cobertura de vegetação ocupando cerca de $5-20 \%$ do total da área do Cerrado, ocorrendo entre afloramentos rochosos em pequenos trechos formados pela decomposição de arenito e quartzito, que geralmente é pobre em nutrientes, apresenta-se ácido e tem baixo teor de matéria orgânica (RIBEIRO; WALTER, 1998).

A Região do Cerrado (figura 1) é de latitude média, presente na região de clima tropical (KOPPEN, 1948). Aproximadamente 90\% dos raios são concentrados nos meses de outubro a abril (período chuvoso) com períodos menos chuvoso de maio a setembro com a umidade chegando a $20 \%$ nos meses de agosto e setembro. Esse período menos chuvoso faz com que o estrato herbáceo-graminoso morto e acumulado no solo se torne bastante seco e facilmente inflamável (MUNHOZ; FELFILI, 2007). Portanto, ao chegar o período chuvoso, onde há muita incidência de raios, estes encontram matéria orgânica seca, que inflamam, ocorrendo o fenômeno natural de fogo no Cerrado.

\footnotetext{
${ }^{1}$ O Cerrado Rupestre é um subtipo de vegetação arbóreo-arbustiva que ocorre em ambientes rupestres litólicos ou rochosos (áreas de afloramento de rochas). Possui cobertura arbórea variável de 5\% a 20\%, altura média de 2 a 4 metros, com estrato arbustivo-herbáceo também destacado. Pode ocorrer em trechos contínuos, mas geralmente aparece em mosaicos, incluído em outros tipos de vegetação. Possui estrutura semelhante ao Cerrado Ralo e um substrato de fácil diferenciação, uma vez que comporta pouco solo entre o afloramento de rocha. Seus solos litólicos são originados da decomposição de arenitos e quartzitos, pobres em nutrientes, ácidos, apresentando também baixos teores de matéria orgânica. No Cerrado Rupestre os indivíduos arbóreos concentram-se nas fendas entre as rochas, e a densidade é variável e dependente do volume de solo. Há casos em que as árvores podem dominar a paisagem, enquanto em outras a flora arbustiva-herbácea predomina; mas ainda assim com árvores presentes (RIBEIRO; WALTER, 1998).
} 


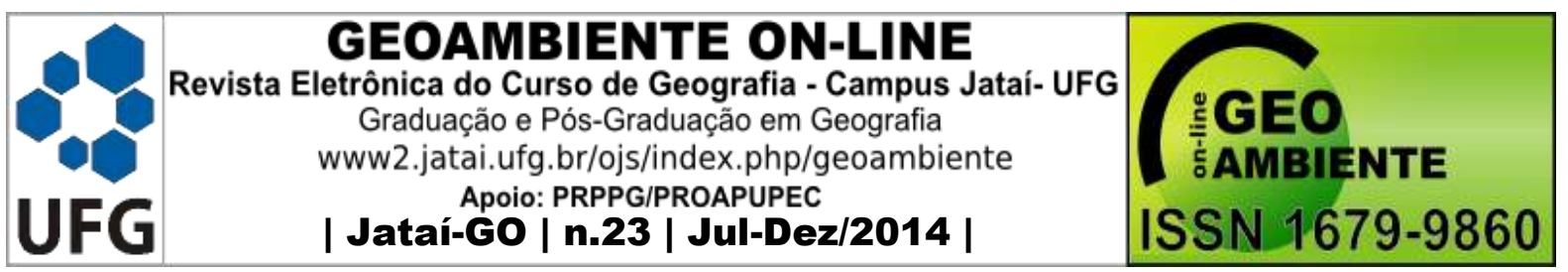

O fogo pode ser de origem natural ou antrópica e, é considerado um distúrbio naturalmente frequente no Cerrado (VICENT, 2004) e na maioria dos sistemas savânicos. Eventos de queima no Cerrado são caracterizados como incêndios de superfície, que consomem o combustível do estrato herbáceo-graminoso (MIRANDA et al., 2002). Alguns estudos já demonstraram que o fogo pode causar sérios efeitos nas populações vegetais por destruírem as flores e frutos de uma planta, órgãos essenciais para a reprodução das plantas e mantimento da estrutura e dinâmica das populações (CARVALHO et al., 2010). Por outro lado é capaz de estimular o florescimento e reprodução de algumas espécies. Tudo isso depende da intensidade do fogo e do nível de destruição dos tecidos vegetais que o fogo acarreta. A queima menos intensa pode promover quebra de dormência das gemas e a deiscência dos frutos, dispersão de sementes de algumas ervas e arbustos e poderia favorecer a germinação de algumas espécies, afetando a reprodução clonal e arquitetura de algumas plantas (COUTINHO, 1978; WHELAN, 1997; SILVA; KLINK, 2001; MUNHOZ; FELFILI, 2007).

Figura 1 - Bioma Cerrado no Brasil

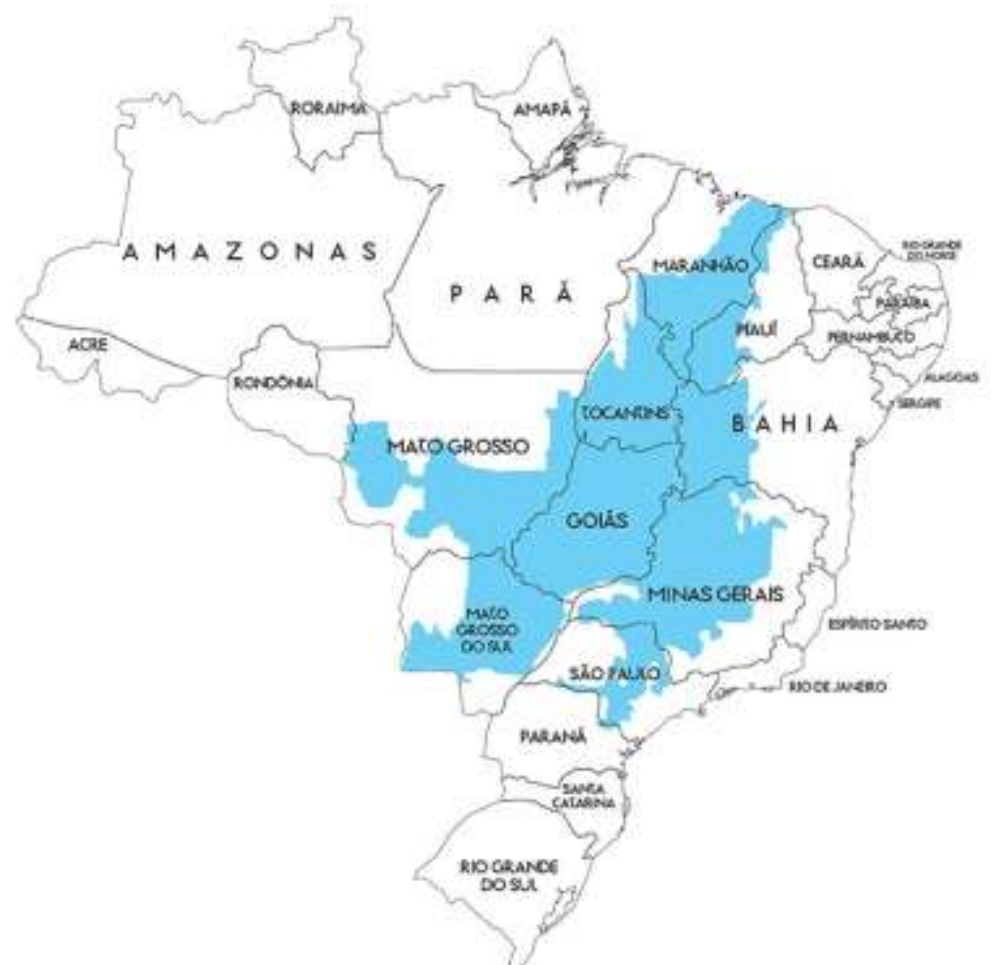

Fonte: EDUCOMMATICA (2013) 


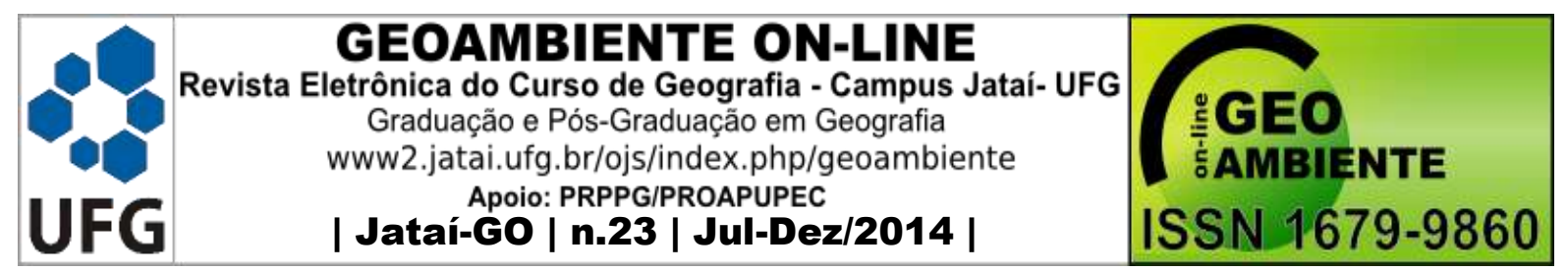

A grande importância do fogo na dinâmica dos ecossistemas e a escassez de informações sobre os seus efeitos nas comunidades vegetais tornam importante os estudos que demonstrem espécies vegetais que sejam influenciadas pelo fogo, principalmente resultando em floração. Essas espécies são consideradas pirofíticas. Conforme a definição de Coutinho (1978), espécie pirofítica é aquela que se encontra bem adaptada a uma condição ambiental que inclui a presença de queimadas, sendo capaz de restaurar rapidamente a parte aérea e iniciar a sua reprodução sexuada. Essa estratégia ecológica é comumente observada em outras espécies subarbustivas de Cerrado (COUTINHO, 1978). Devido à importância das espécies pirofíticas para o domínio Cerrado, especialmente o Cerrado Rupestre, esse estudo objetiva identificar a composição florística de comunidades que florescem após a passagem do fogo.

\section{MATERIAL E MÉTODOS}

Os estudos foram conduzidos no final da estação menos chuvosa (18, 19 e 20 de Setembro de 2012) em uma área queimada, em setembro de 2012, de Cerrado Rupestre, no entorno do Parque Nacional da Chapada dos Veadeiros, Goiás, Brasil (Figura 2; $14^{\circ} 10^{\prime} 45.89^{\prime \prime} \mathrm{S}$ e $\left.47^{\circ} 49^{\prime} 13.37^{\prime \prime} \mathrm{W}\right)$. A área em foco foi queimada acidentalmente por causas desconhecidas. O entorno da área queimada foi percorrido, em busca de espécies que estavam em estado reprodutivo. Porém, não foram encontradas espécies em florescimento ou com frutos nas áreas não queimadas.

Todos os indivíduos que se encontravam em estado reprodutivo (botões florais, flores e frutos) na área foram fotografados e coletados para identificação mais precisa. Os materiais foram herborizados e depositados no Herbário do Jardim Botânico de Goiânia (GO). Foi realizada observação focal para visualizar visitantes florais em Dyckia cf. areniticola Leme, por ser a planta em floração mais comum na área. As observações foram realizadas das 5 às 9 horas da manhã e das 15 às 18 horas de cada dia, totalizando aproximadamente 24 horas de observação de acordo com a metodologia proposto por Silva e Santos (2008).

As espécies encontradas nessa área foram buscadas no banco de dados da Flora do Brasil (2013), para saber o status de ameaça das mesmas, e se são endêmicas ou não, da região e do bioma Cerrado. 


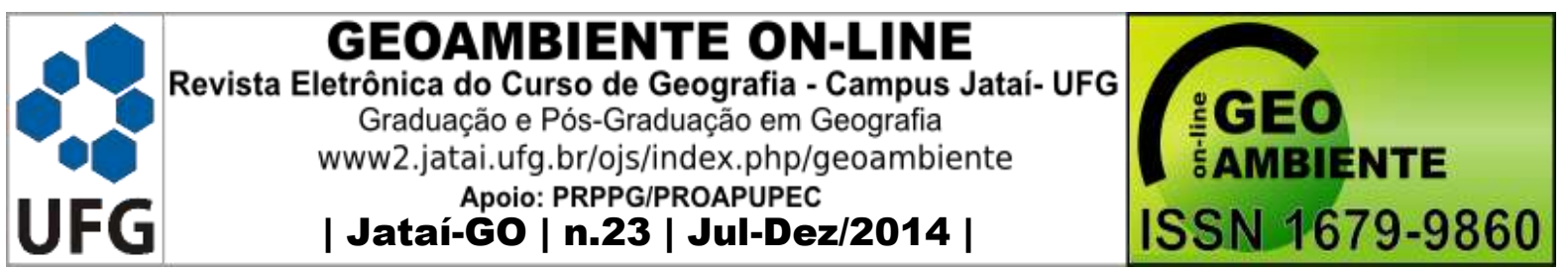

Figura 2 - Mapa da localização do Parque Nacional da Chapada dos Veadeiros (Estado de Goiás)
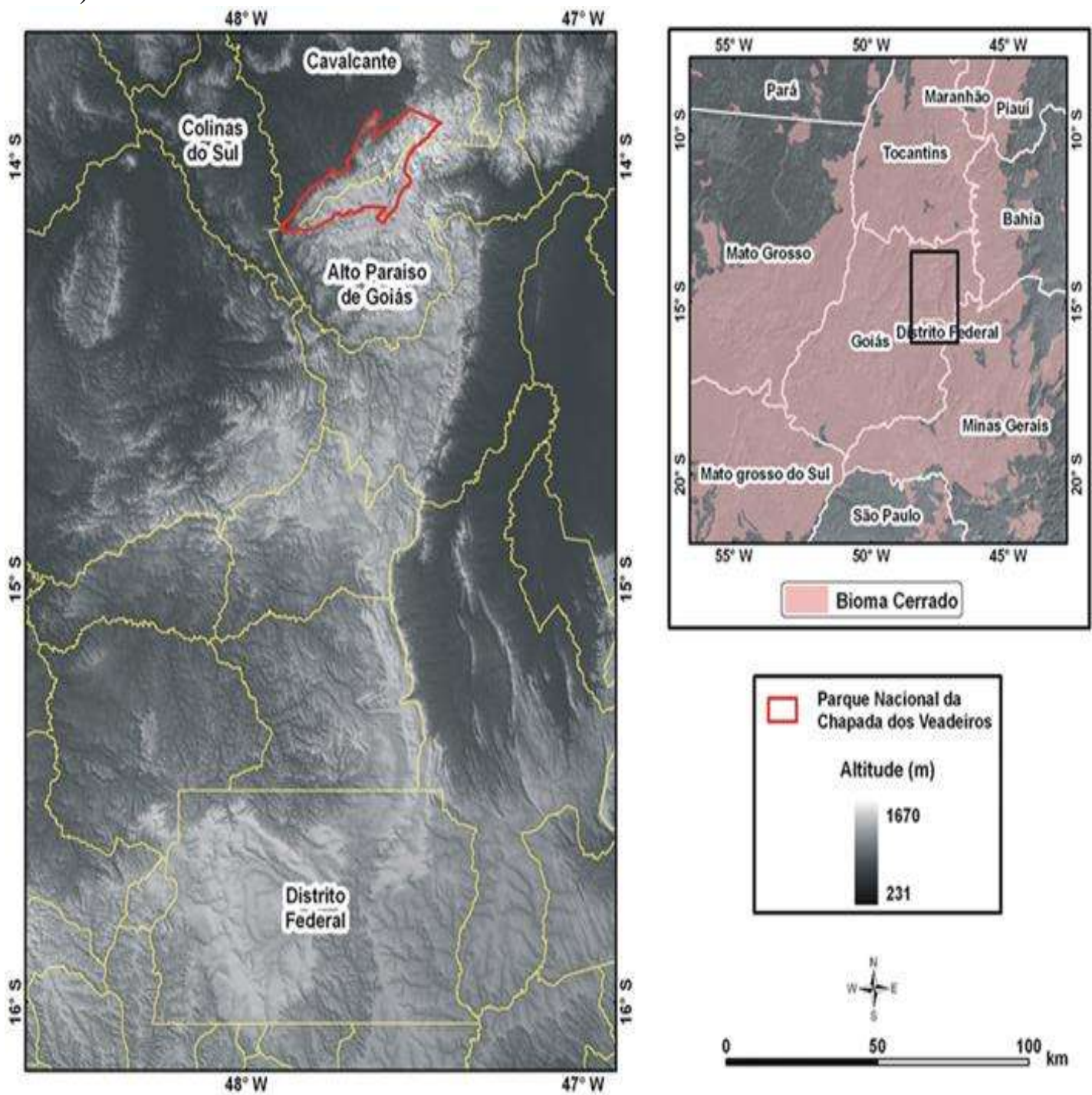

Fonte: Carvalho Júnior et. al. (2008)

\section{RESULTADOS E DISCUSSÃO}

No total foram encontradas 16 espécies (Tabela 1 e Figuras 3 e 4) em estado reprodutivo, de 15 gêneros diferentes e 11 famílias botânicas. As famílias que tiveram maior número de espécies encontradas na área são as Amaranthaceae (3); Asteraceae; Bromeliaceae e Cyperaceae (todas apresentando duas espécies cada). O principal gênero encontrado foi Gomphrena com duas espécies. As famílias Amaranthaceae e Asteraceae são conhecidas por apresentarem espécies consideradas pirofíticas. Essas famílias possuem características como estruturas espessadas (exempo: xilopódios) que armazenam substâncias de reserva possibilitando a recuperação da parte vegetativa e o aparecimento das estruturas reprodutivas (SIQUEIRA, 1992; SIQUEIRA, 2007; CARVALHO et al., 2010). 


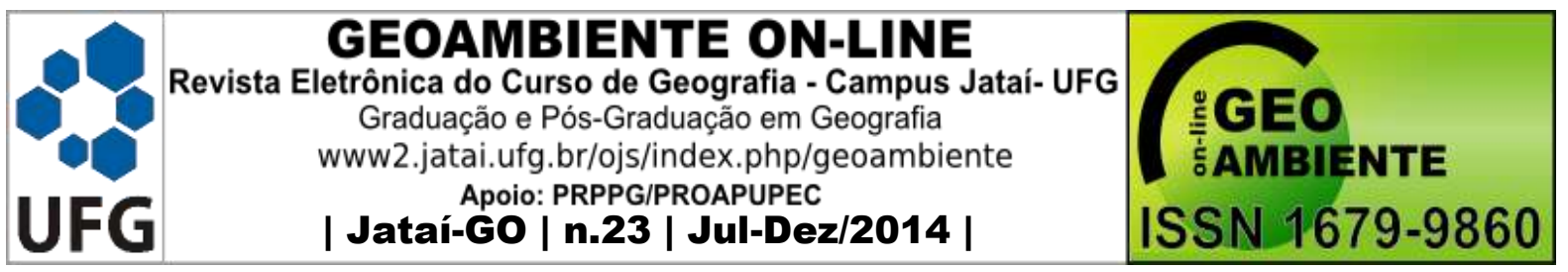

Tabela 1. Espécies Pirofíticas Encontradas no Entorno do Parque Nacional da Chapada dos Veadeiros - Estado de Goiás

\begin{tabular}{|c|c|}
\hline Família botânica & Espécie \\
\hline Amaranthaceae & $\begin{array}{c}\text { Gomphrena cf. lanigera Pohl ex Moq. } \\
\text { Gomphrena } \mathrm{sp.} \\
\text { Pfaffia } \mathrm{sp.}\end{array}$ \\
\hline Asteraceae & $\begin{array}{c}\text { Inulopsis camporum Gardner G.L. Nesom } \\
\text { Ichthyothere sp. }\end{array}$ \\
\hline Bromeliaceae & $\begin{array}{c}\text { Bromelia glaziovii } \mathrm{Mez} \\
\text { Dyckia cf. areniticola Leme }\end{array}$ \\
\hline Cyperaceae & $\begin{array}{c}\text { Bulbostylis paradoxa (Spreng.) Lindm. } \\
\text { Rhynchospora } \mathrm{sp.}\end{array}$ \\
\hline Euphorbiaceae & Euphorbia sp. \\
\hline Nyctaginaceae & Guapira sp. \\
\hline Orchidaceae & Cyrtopodium sp. \\
\hline Polygalaceae & Polygala poaya Mart. \\
\hline Rhamnaceae & Crumenaria choretroides Mart. ex Reissek \\
\hline Velloziaceae & Vellozia variabilis Mart. ex Schult \\
\hline Verbenaceae & $\mathrm{sp}$ \\
\hline
\end{tabular}

Fonte: Autores (2012) 


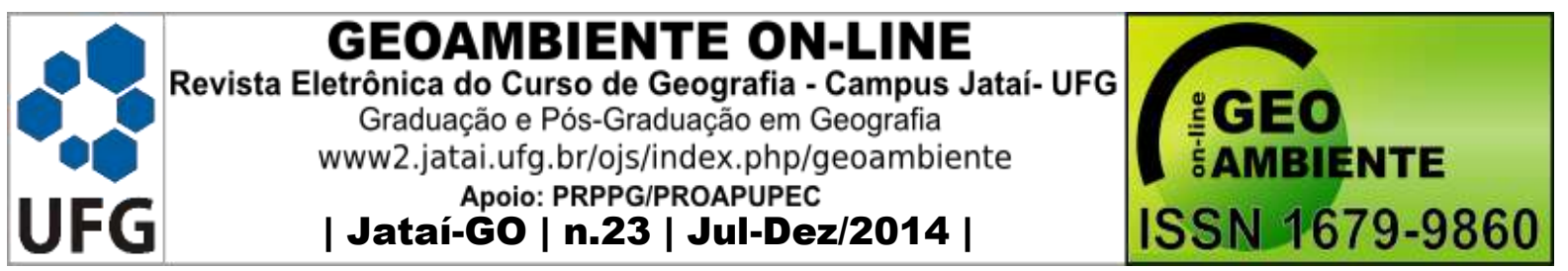

Figura 3 - Espécies registradas no entorno da Chapada do Veadeiros florescendo após ocorrência do fogo - - A. Verbenaceae; B. Nyctaginaceae; C. Pfaffia sp. (Amaranthaceae); D. Euphorbia sp. (Euphorbiaceae); E. Gomphrena cf. lanigera Pohlex Moq. (Amaranthaceae); F. Crumenaria choretroides Mart. ex Reissek (Rhamnaceae); G. Inulopsis camporum Gardner G. L. Nesom (Asteraceae); H. Gomphrena sp. (Amaranthaceae); I. Rhynchospora sp. (Cyperaceae); J. Ichthyothere sp. (Asteraceae); K. Bromelia glaziovii Mez (Bromeliaceae); L. Cyrtopodium sp. (Orchidaceae); M. Bulbostylis paradoxa (Spreng.) Lindm. (Cyperaceae); N. Dyckia cf. areniticola Leme (Bromeliaceae); O. Polygala poaya Mart. (Polygalaceae).

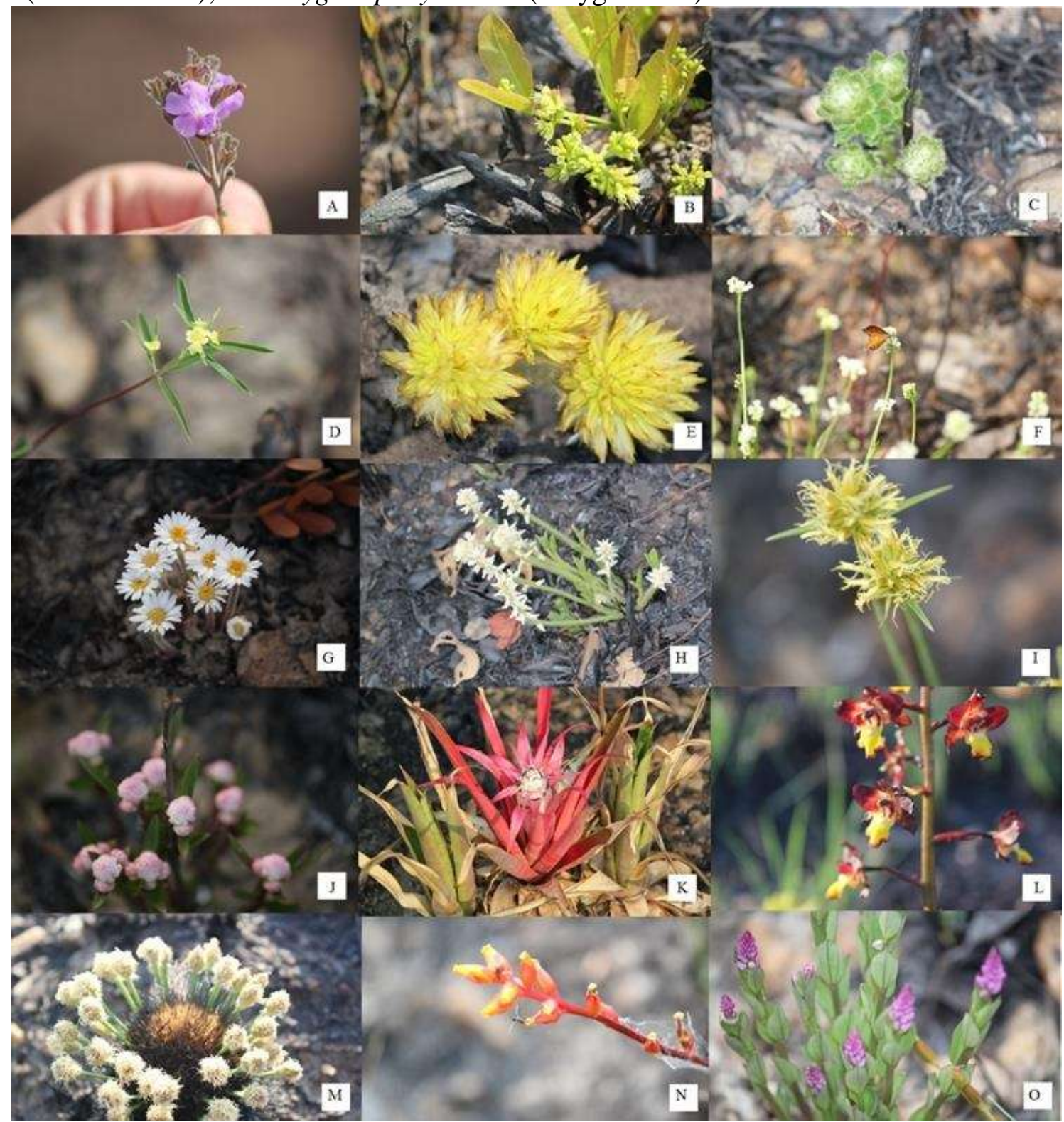

Fonte: Autores, 2012 


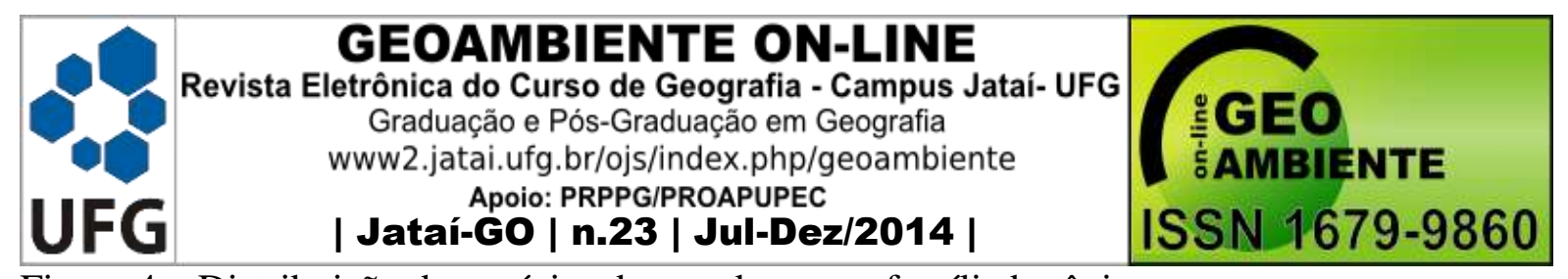

Figura 4 - Distribuição de espécies de acordo com a família botânica

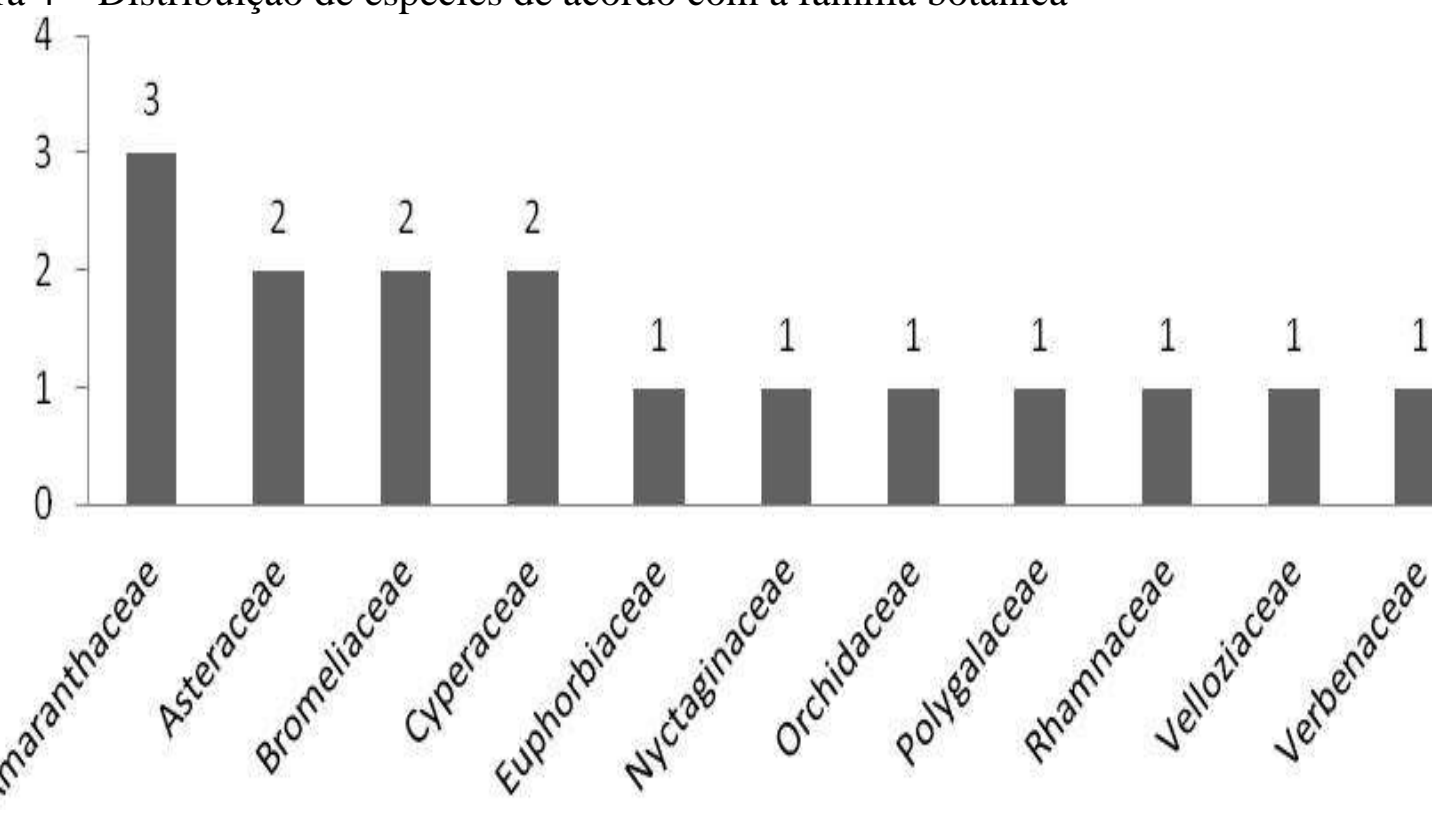

Fonte: Autores, 2012

Dentre as espécies vegetais, quatro são endêmicas para o Cerrado (Inulopsis camporum; Gomphrena cf. lanigera; Crumenaria choretroides e Bromelia glaziovii), sendo que G. lanigera e B. glaziovii só ocorrem em Goiás e Minas Gerais. Além disso, Dyckia cf. areniticola é considerado nova ocorrência para o Estado de Goiás conforme a comparação realizada em Flora do Brasil (2013). A camada rasteira possui diversidade de cerca de quatro a sete vezes o número das espécies lenhosas (arbustos maiores e árvores), sendo mais representativas as famílias Asteraceae, Gramineae, Fabaceae e Rubiaceae (RATTER et al., 1997). Dessa forma, essa riqueza de espécies e famílias mais abundantes também apresentam representantes na comunidade vegetal pirofitíca.

O comportamento pirofítico de G. lanigera também foi enfatizado por Siqueira (1992), que informa a ocorrência da espécie em áreas de Cerrados e campos rupestres de Goiás, Minas Gerais e Distrito Federal, aparecendo frequentemente após queimadas. A rápida floração das espécies herbáceas de Amaranthaceae, resultando na dispersão anemocórica dos frutos, favorece o estabelecimento pioneiro em áreas mais distantes, antes mesmo da recuperação integral do restante da vegetação rasteira, composta especialmente por gramíneas e ciperáceas, que apresentam rápido re-estabeclecimento após o fogo (CARVALHO et al., 2010). 


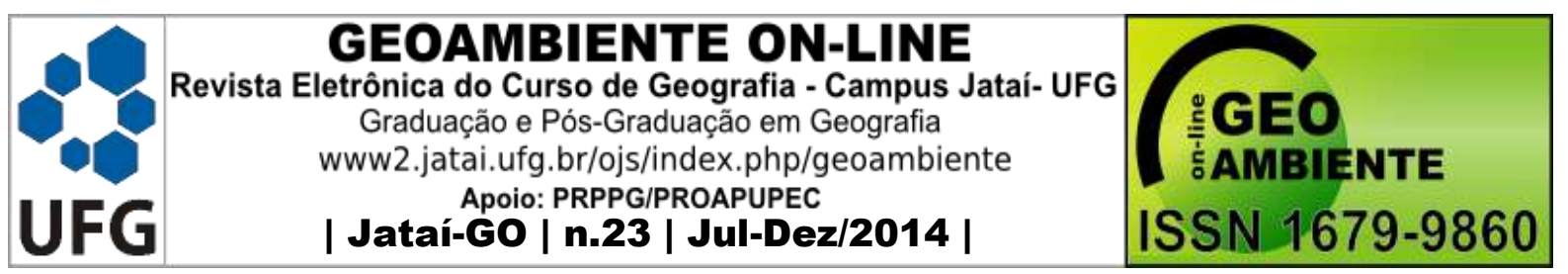

Exceto pelas espécies da família Cyperaceae (Rhynchospora sp. e Bulbostylis paradoxa), que é anemófila, todas as outras espécies florescem e fornecem recursos para visitantes florais e polinizadores. Recursos esses que se tornam essenciais em uma área que não apresenta alternativas alimentares (SILVA; SANTOS, 2008). Dentre os visitantes florais observados em Dyckia cf. areniticola foram encontrados diversas himenópteras (borboletas e formigas), lepidópteras (Figuras 5 e 6 ) e até mesmo beija-flores alimentando-se dos recursos florais.

Figura 5 - Visitantes florais de Dyckia: (A) Colibri serrirostris (Fêmea); (B) Heliactin bilophus (Fêmea); (C) Dialictussp.; (D) Borboleta 1; (E) Xylocopa sp.; (F) Nectário floral; (G) Formiga em mutualismo.

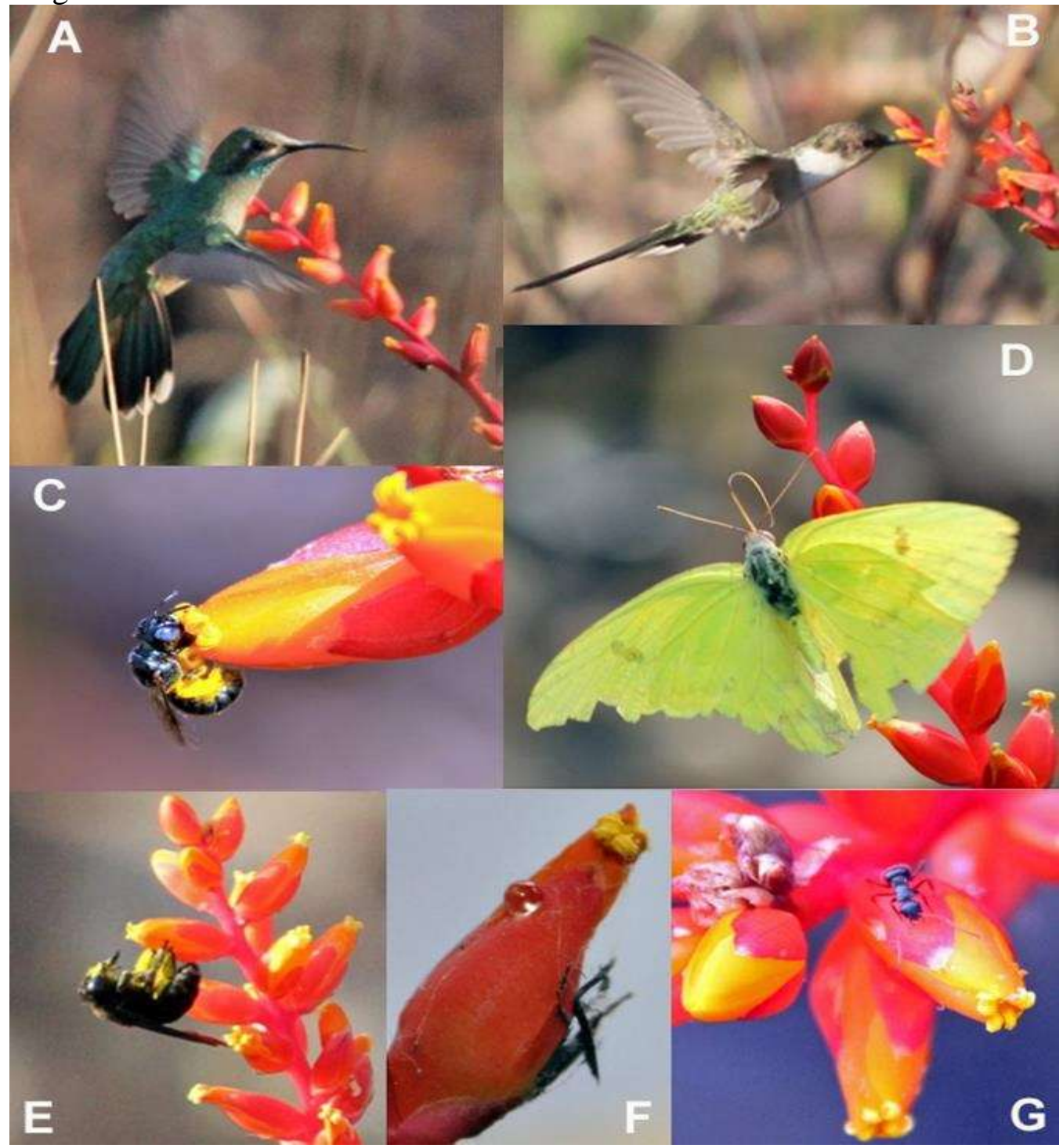

Fonte: Autores, 2012. 


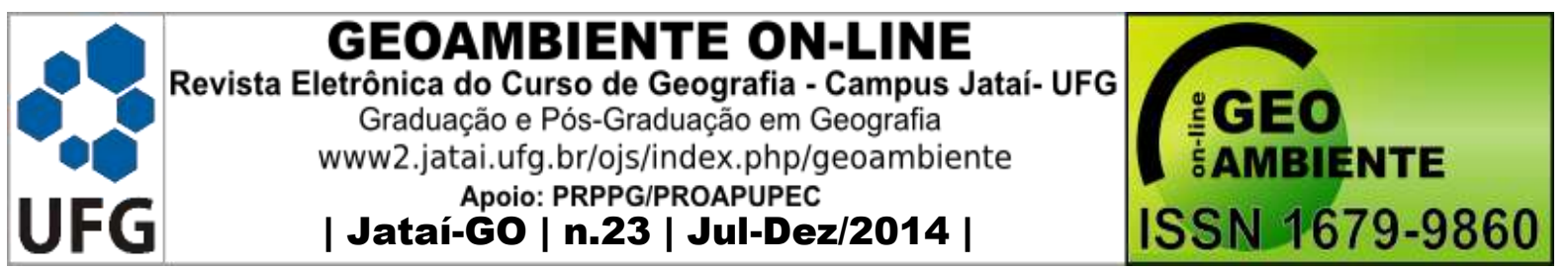

Figura 6 - (A; B) Lepidopteras visitando Crumenaria choretroides Mart. ex Reissek; (C) Formigas (Camponotus sp.) visitante Bromelia glaziovii Mez; Halictidae; (D) Apis mellifera L. (E) visitando Nyctaginaceae.

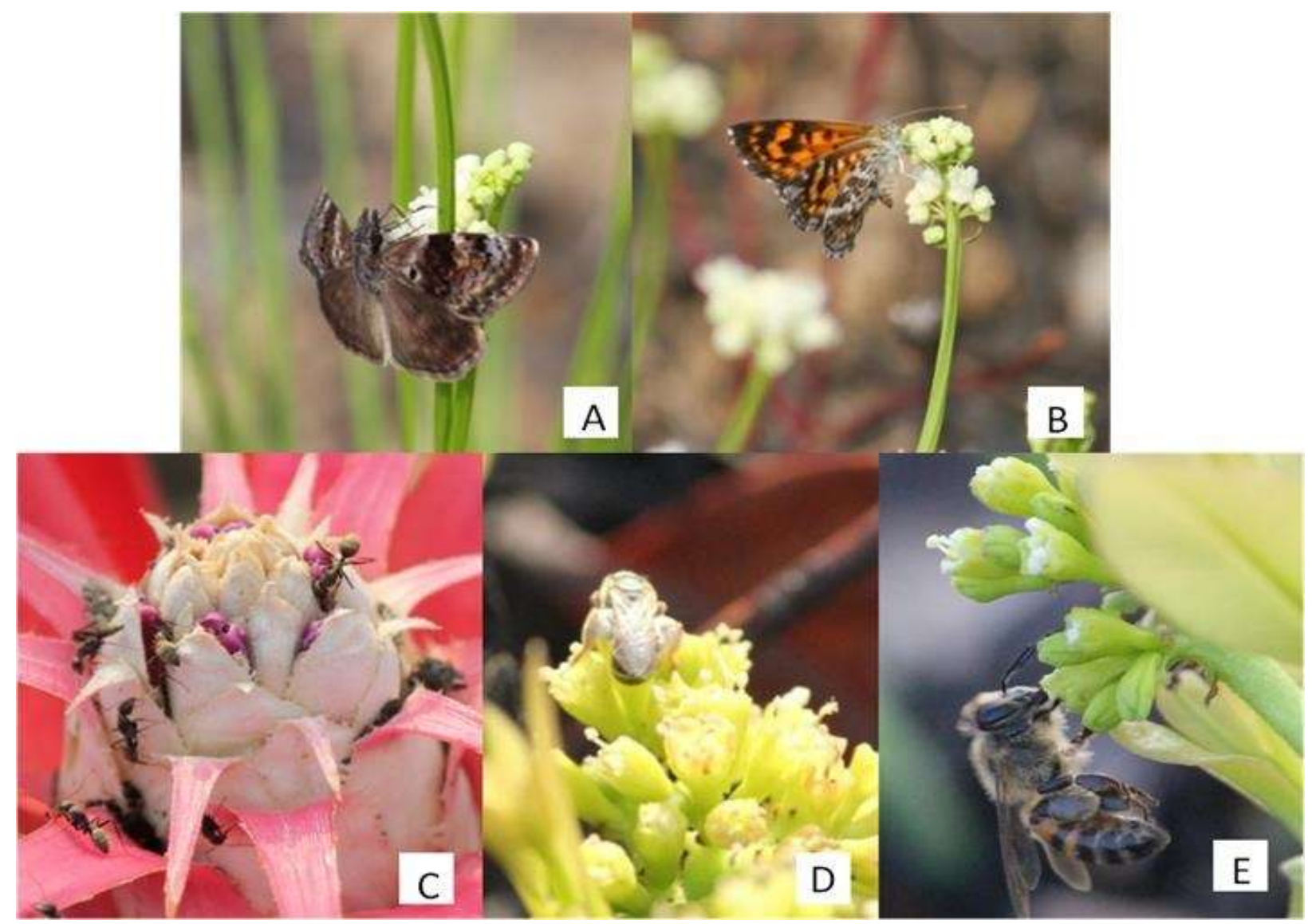

Fonte: Autores, 2012

O estudo da ecologia das espécies dessa camada da vegetação é importante para ampliar o conhecimento sobre a vegetação que recobre as áreas abertas de Cerrado. Nas plantas, o sistema subterrâneo desenvolvido, a dispersão anemocórica e o pirofitismo são adaptações consideradas importantes para a sobrevivência das espécies (SIQUEIRA, 2007).

O fogo deve quebrar a dormência de G. lanigera - além de outras espécies já estudadas como de Froelichiella grisea, G. prostrata, G. hermogenesii e Pfaffia sp. -estudados por Carvalho et al. (2010), estimulando tanto a rebrota das porções aéreas quanto a floração e frutificação. Essas observações são compatíveis com as observações realizadas para outras espécies dessa família (SIQUEIRA, 1992; CARVALHO et al., 2010).

A intensidade e frequência de incêndios, o tipo e a quantidade de combustível, a matriz onde está inserida a área atingida, a topografia, o vento, a temperatura e a umidade 


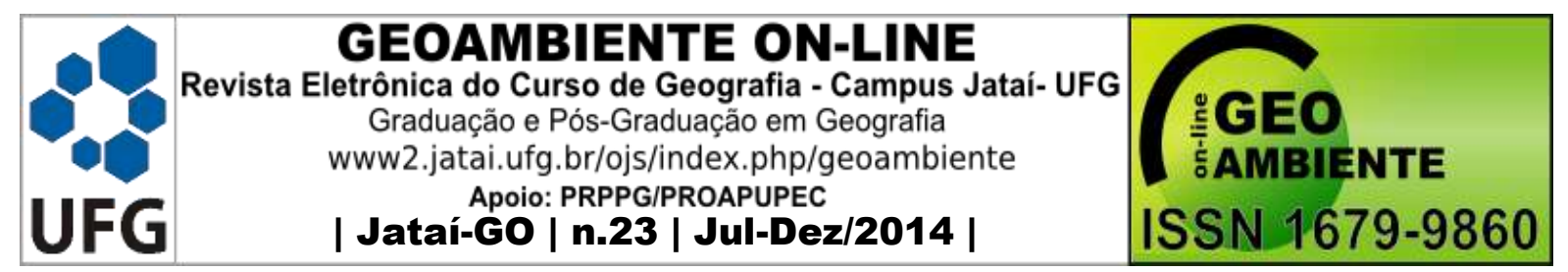

podem interferir, diferentemente, na ecologia e na estratégia reprodutiva de determinada espécie (WHELAN, 1997; SILVA; SANTOS, 2008; CARVALHO et al., 2010).

\section{CONCLUSÃO}

O fogo no bioma Cerrado contribui para rebrota e florescimento das espécies vegetais, contribuindo para a reocupação do local pós-queimada (16 espécies vegetais na área). A floração ainda é fonte alimentar de diversas espécies de visitantes florais (abelhas e beijaflores), contribuindo para a dinâmica energética da comunidade como um todo. Além disso, esse estudo contribui para o banco de registros botânicos, pois revela nova ocorrência de Dyckia cf. areniticola Leme no Estado de Goiás.

\section{REFERÊNCIAS}

CARVALHO JUNIOR A. O.; OSMAR, SAMPAIO C. S.; SILVA N. C.; COUTO JÚNIOR A. F.; GOMES R. A. T.; CARVALHO A. P. F.; SHIMABUKURO Y. E. Classificação de padrões de savana usando assinaturas temporais NDVI do sensor MODLS no Parque Nacional Chapada dos Veadeiros. Revista Brasileira de Geofísica, v. 26, n. 4, p. 505-517, 2008.

COUTINHO, L. M. Aspectos ecológicos do fogo no Cerrado: a temperatura do solo durante as queimadas. Revista Brasileira de Botânica, n. 1, p. 93-96, 1978.

CARVALHO, S. M. F.; MARCHIORETTO, M. S.; BÁO, S. N. Anatomia foliar, morfologia e aspectos ecológicos das espécies da família Amaranthaceae da Reserva Particular do Patrimônio Natural Cara Preta, em Alto Paraíso, GO, Brasil. Biota Neotropical, v. 10, n. 4, p. 77-86, 2010. Disponível em: <http://www.scielo.br/pdf/bn/v10n4/11.pdf>. Acesso em: $12 / 10 / 2012$.

FELFILI, J. M.; REZENDE, A. V.; SILVA JÚNIOR, M. C. Biogeografia do Bioma Cerrado: vegetação e solos da Chapada dos Veadeiros. Brasília: EdUnB - FINATEC, 2007.

FLORA DO BRASIL. Lista de espécies da Flora do Brasil. Disponível em: <http://floradobrasil.jbrj.gov.br/jabot/listaBrasil/ConsultaPublicaUC/ConsultaPublicaUC.do>. Acesso em: 02/06/2013.

KOPPEN, W. Climatologia: con un estudio de los climas de la tierra. Ciudad de Mexico: Fondo de Cultura Economica, 1948. 


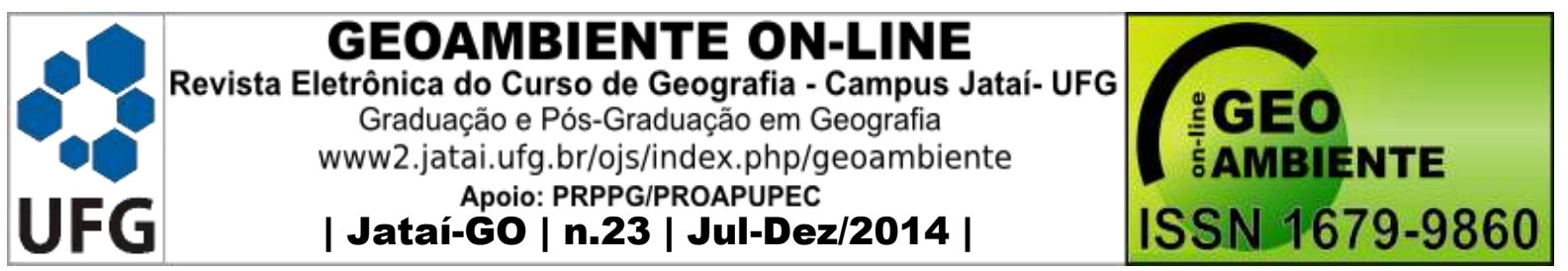

MIRANDA, H. S.; BUSTAMANTE, M. M. C.; MIRANDA, A. C. The Fire Factor. In: OLIVEIRA O. S.; MARQUIS, R. J. The Cerrados of Brazil: ecology and natural history of a neotropical savanna. New York: Columbia University Press, 2002.

MUNHOZ, C. B. R.; FELFILI, J. M. Reproductive phenology of an herbaceous-subshrub layer of a Savannah (Campo Sujo) in the Cerrado Biosphere Reserve I, Brazil. Brazilian Journal of Biology, v. 67, n. 2, p. 299-307, 2007. Disponível em: <http://www.scielo.br/pdf/bjb/v67n2/14.pdf>. Acesso em: 02/05/2013.

RATTER, J. A.; RIBEIRO, J. F.; BRIDGEWATE, S. The brazilian cerrado vegetation and threats to its biodiversity. Annals of Botany. n. 80, p. 223-230, 1997.

RIBEIRO, J. F; WALTER, B. M. T. Fitofisionomias do Bioma Cerrado. In: SANO, S. M.; ALMEIDA, S. P. Cerrado: ambiente e flora. Planaltina (DF): EMBRAPA, p. 89-166, 1998.

SILVA, D. A.; KLINK, C. A. Dinâmica de foliação e perfilhamento de duas gramíneas $C_{4} e$ uma $C_{3}$ nativas do Cerrado. Revista Brasileira de Botânica, v. 24, n. 4, p. 441 - 446, 2001. Disponível em: $\quad<$ http://www.scielo.br/scielo.php?script=sci_arttext\&pid=S010084042001000400010>. Acesso em: 04/04/2013.

SILVA, C. S. P.; SANTOS, M. L. Comportamento fenológico no evento pós-queima e biologia reprodutiva de Spiranthera odoratissima A. St.-Hil. (Rutaceae). Biotemas, v. 21, n. 1, p. 29-39, 2008. 2 Disponível em: <https://periodicos.ufsc.br/index.php/biotemas/article/view/2175-7925.2008v21n1p29>. Acesso em: 07/03/2013.

SIQUEIRA, J. C. O gênero Gomphrena L. (Amaranthaceae) no Brasil. Pesquisa Botânica, n. 43, p. 51-97, 1992.

SIQUEIRA, J. C. O Bioma Cerrado e a preservação de grupos taxonômicos: um olhar sobre as Amaranthaceae. Pesquisa Botânica, n. 58, p. 389-394, 2007.

VICENT, R. C. Florística, fitossociologia e relações entre a vegetação e o solo em áreas de Campos Ferruginosos no Quadrilátero Ferrífero, Minas Gerais. 145 f. Tese (Doutorado em Ecologia) - Instituto de Biociências, Universidade de São Paulo, São Paulo, 2004.

WHELAN, R. J. The ecology of fire. Cambridge: Cambridge University Press, 1997. EDUCOMMATICA. Biomas. Disponível em: <http://www.biomabilidade.com.br/biomas/>. Acesso em: 12/07/2013. 